\title{
Apresentação de dossiê: Estado, mercado e desenvolvimento
}

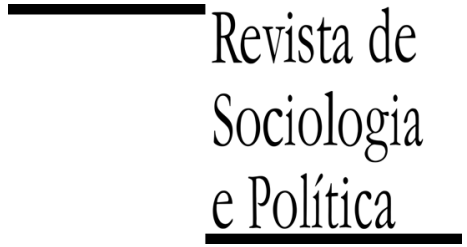

DOI 10.1590/1678-987315235501

\author{
Cristiano Fonseca Monteiro e Tomás Undurraga
}

Recebido em 12 de Janeiro de 2015. Aceito em 12 de Fevereiro de 2015.

\section{Apresentação}

$\mathrm{O}$ principal objetivo deste dossiê é explorar as interfaces da Sociologia Econômica com a Ciência Política, por meio de trabalhos que tratam, genericamente, da relação entre Estado e mercado, e mais especificamente, que discutem os mecanismos e instituições que regulam, promovem ou limitam a interação entre agências públicas e agentes privados. Busca-se promover uma reflexão sobre o papel do Estado, das elites econômicas e de outros agentes sociais relevantes em um contexto de redefinição das estratégias de desenvolvimento.

Dois pontos de partida inspiram este dossiê. O primeiro é a convicção de que as relações entre Estado, mercado e desenvolvimento continuam no centro das controvérsias e desafios na América Latina e dos países em desenvolvimento. A despeito dos ciclos políticos, especificidades regionais e terminologias da moda, os conflitos latentes e manifestos entre as orientações neoliberais e neodesenvolvimentistas permanecem no centro das disputas políticas e econômicas latino-americanas. O segundo é conectar uma série de pesquisas empíricas que estão na intersecção entre a Sociologia Econômica e a Ciência Política e que, de perspectivas teóricas plurais, buscam responder velhas perguntas sobre a América Latina a partir de novas perspectivas. Neste esforço, inclui-se um trabalho comparativo com a África do Sul, ampliando a reflexão para o âmbito dos países em desenvolvimento. Estratégias de desenvolvimento e a retomada do ativismo estatal; mecanismos de concertação, diálogo social e tripartismo; atuação política dos empresários entre o particularismo e a solidariedade social; e o papel dos especialistas e elites tecnocráticas no conhecimento econômico são todos temas consagrados na agenda de pesquisa das Ciências Sociais. A novidade está na forma como essas perguntas são respondidas com novas ferramentas teóricas, muitas delas produzidas num contexto diferente dos países da região, lançando novas luzes sobre essas incógnitas.

Um segundo objetivo do dossiê diz respeito ao esforço de articulação entre diferentes redes de pesquisa em Sociologia Econômica, visando aumentar o intercâmbio e a colaboração entre elas. Assim, os autores reunidos neste volume estiveram em diferentes espaços dedicados à Sociologia Econômica em encontros no Brasil (Grupos de Trabalho "Sociologia Econômica" do XVI Congresso Brasileiro de Sociologia e "Sociedade e Vida Econômica" do $38^{\circ}$ Encontro Anual da Associação Nacional de Pós-Graduação e Pesquisa em Ciências Sociais) e no exterior ( $26^{\circ}$ Encontro Anual da Society for the Advancement of Socio-Economics e no Grupo de Trabalho "Sociología Económica" do XXIX Congresso Latino-Americano de Sociologia), além da rede latino-americana de colaboradores do blog Estudos de La Economía. Em todos esses fóruns, o tema específico deste dossiê tem sido objeto de reflexão e debate, de modo que sua publicação reflete a importância do tema dentro da agenda mais geral desse 
campo que, esperamos, torne-se cada vez mais aberto à interlocução entre os participantes dessas diversas redes.

A discussão sobre o papel do Estado e mercado no desenvolvimento nacional está inscrita na tradição sociológica da América Latina, sendo esta a região privilegiada pela maioria dos artigos do dossiê. A consolidação da Sociologia latino-americana teve como um dos seus traços marcantes a análise da trajetória distintiva por meio da qual a região se incorporou ao sistema capitalista mundial (Wallerstein 1979). De um lado, abordagens funcionalistas se perguntaram sobre os padrões que sociedades tradicionais deveriam seguir para "desenvolver-se" no sentido da modernidade industrial (Germani 1964; Parsons 1964) e, de outro, abordagens estruturalistas explicavam o atraso latino-americano não pelas deficiências no processo de industrialização, mas pelas desvantagens nos termos de intercâmbio comercial entre os países desenvolvidos do centro e os subdesenvolvidos da periferia (Prebisch 1950). As ideias de Prebisch foram amadurecidas por pesquisadores da CEPAL ao longo da década de 1960, culminando nas formulações da teoria da dependência (Pinto 1959; Ahumada 1958; Furtado 1964; Cardoso \& Faletto 1969), a qual enfatizou as condições de intercâmbio econômico e a integração dos países ao sistema global. É no contexto do desenvolvimentismo cepalino que se consolidou a estratégia de industrialização por substituição de importações, favorecendo a propriedade estatal das indústrias, controles de preços pelo governo e gestão macroeconômica orientada para moderar o ciclo de negócios e promover compromissos de classe (Montecinos \& Markoff 2009).

Na tradição sociológica brasileira, esse tema foi estudado seja como um aspecto particular das relações entre público e privado dentro da trajetória de modernização do Brasil (Hollanda 1936; Faoro 1975), seja como um objeto privilegiado de análise do que Florestan Fernandes chamou de "a revolução burguesa no Brasil" (Fernandes 1976). Pesquisas empíricas do período reafirmaram a centralidade do tema, colocando em foco o papel das elites empresariais e estatais neste processo (Ianni 1965; Martins 1968; Cardoso 1972), tendo o já citado Dependência e desenvolvimento (Cardoso \& Faletto 1969) representado um ponto alto desta trajetória.

No entanto, o modelo desenvolvimentista latino-americano encontrou seus limites à medida que as crescentes demandas por mudanças sociais e políticas esbarraram na incapacidade do Estado de enfrentá-las, causando uma tensão social crescente. A polarização social levou à ruptura da ordem institucional em muitos países da região, inaugurando uma onda de regimes autoritários. Em alguns casos, foi no próprio interior dos regimes autoritários que se produziram os primeiros experimentos neoliberais, como nos casos do Chile e da Argentina. Em outros casos, como o brasileiro, a redemocratização trouxe consigo a renovação das expectativas em torno do Estado, desta vez destacando-se seu papel de garantidor de uma série de direitos sociais, conforme expresso na Constituição de 1988. No entanto, assim como em outros países da região, a crise fiscal e a hiperinflação formariam o cenário para a entrada em cena das reformas neoliberais.

Em geral, essas reformas promoveram o retraimento do Estado e ampliaram o papel dos mercados na atividade econômica, compreendendo liberalização dos fluxos de investimento direto estrangeiro, abertura comercial, reforço do papel do setor privado através da privatização e desregulamentação, flexibilização do mercado de trabalho, equilíbrio fiscal e inflação baixa (Chang \& Grabel 2004). Em termos de produção, o neoliberalismo teve como resultado a desindustrialização, reforçando o papel latino-americano tradicional na divisão internacional do trabalho ligado à exportação de produtos primários (como a agricultura, aquicultura e mineração), em busca de "vantagens comparativas". 
${ }^{1}$ Ver, por exemplo, os ensaios reunidos em Gentili (2000).

${ }^{2}$ Para uma discussão mais aprofundada do conceito de neoliberalismo, para além da questão geral do "retraimento do Estado", ver Undurraga (2014, cap. 4).
Os programas de industrialização, ícones dos projetos desenvolvimentistas nos anos 1970, perderam força em casos como o Brasil, Argentina e México, e foram completamente esvaziados em outros casos, como no Chile (Domingues 2008).

A globalização trouxe novos desafios à análise sociológica e política dos fenômenos econômicos. Por um lado, diversos estudos deram ênfase à perda de direitos, precarização das relações de trabalho e construção de novas formas de dominação do capital por trás das promessas da globalização ${ }^{1}$. Com um viés de denúncia, muitas dessas análises cumpriram um papel importante para chamar atenção para os riscos que o novo padrão competitivo do capitalismo globalizado colocava para os trabalhadores e comunidades locais. A maior liberdade na circulação do capital, assim como a reestruturação da produção por meio de redes transnacionais deixaria os atores locais sem escolha: adaptar-se aos novos padrões deste capitalismo competitivo ou correr o risco de desligamento do jogo. Não obstante, a despeito do seu caráter crítico, esse tipo de abordagem acabava por chegar a um diagnóstico semelhante ao do discurso da globalização que pretendiam criticar: a inevitabilidade do processo em curso, cujo corolário seria a convergência para um modelo único de "economia de mercado". Desde essa perspectiva, o neoliberalismo aparecia como um programa relativamente homogêneo, ideologicamente amparado no que ficou conhecido como o "Consenso de Washington", consistindo em um programa de "retraimento do Estado", disciplina fiscal e abertura comercial que norteou as políticas governamentais em diversos países no período ${ }^{2}$.

Contrariando a tese sobre a convergência, autores como Eli Diniz exploraram os aspectos multifacetados da globalização, salientando a permanência da dimensão política como variável-chave para se pensar as trajetórias de inserção no processo de globalização, assim como os desafios que o novo contexto trouxe para a democracia, governabilidade e para os padrões de articulação entre Estado e sociedade (Diniz 2000). Essa perspectiva introduziu uma agenda de pesquisa sobre as trajetórias específicas, notadamente do ponto de vista setorial, mostrando como distintas formas de articulação entre Estado e mercado emergiram entre as décadas de 1990 e 2000 (Monteiro 2010; Leme 2009; Undurraga, neste volume; Maillet, neste volume). Por esse prisma, em vez de convergência, tais estudos confirmaram a hipótese da especificidade das trajetórias em direção ao neoliberalismo, como resultado da combinação de escolhas por partes de atores estratégicos e processos estruturais. A década de 2000, com a chegada ao poder de lideranças de centro-esquerda em vários países latino-americanos, colocaria de lado as perspectivas mais fundamentalistas sobre a globalização e, além disso, reintroduziria o "papel do Estado" na promoção do desenvolvimento.

Em muitos países da região, a renovação dos movimentos sociais, com a mobilização de setores sociais tão diversos tais como empregados, pensionistas, indígenas e de vizinhança, entre outros, aprofundou as demandas por redistribuição de renda, reforma agrária e urbana, contribuindo para consolidar a agenda de ativismo estatal, tanto no âmbito econômico como nas políticas sociais (Silva 2009). Enquanto alguns autores viram nesses movimentos o abandono da agenda neoliberal em prol de uma agenda "neodesenvolvimentista", outros falaram de um "neoliberalismo temperado", combinando políticas pró-mercado com programas sociais de redução da pobreza. As respostas nas políticas públicas de âmbito local, de proteção social e de direitos indígenas, impulsionadas por governos de centro-esquerda e movimentos sociais democráticos diluíram de maneira crescente os princípios do Consenso de Washington. Tais mudanças levaram ao debate sobre a entrada em uma era "pós-neoliberal" na América Latina, desafiando a monopolização tecnocrática do espaço 
${ }^{3}$ É o caso dos trabalhos de Cruz (2010) sobre a regulação no setor de saúde suplementar, de Monteiro (2009) sobre o setor aéreo e, mais recentemente, os diversos trabalhos reunidos em Gomide e Pires (2014) demonstrando as realizações e também os diversos limites enfrentados por projetos de promoção do bem-estar e desenvolvimento econômico tão diversos quanto o "Minha Casa, Minha Vida", a revitalização da indústria naval e o próprio Bolsa Família. político e buscando favorecer o papel do Estado no desenvolvimento nacional (Burdick, Oxhorn \& Roberts 2009; Macdonald \& Ruckert 2009).

No Brasil, especificamente, a eleição de Lula em 2002 e a retomada de uma agenda de maior ativismo estatal reposicionou a questão da relação entre "Estado, mercado e desenvolvimento". Neste contexto surgem referências a um "novo desenvolvimentismo" (Bresser-Pereira 2007), entendido como contraponto conceitual ao ideário neoliberal e tendo como fundamento a construção de projetos nacionais de desenvolvimento em que o Estado tem um papel ativo na promoção de políticas industriais, articulação com agentes privados e redução das desigualdades, mantendo ao mesmo tempo compromisso com a estabilidade macroeconômica. Trata-se, nesse sentido, da busca de estratégias próprias de inserção no capitalismo global, recusando as interpretações fatalistas mencionadas anteriormente (Diniz 2007).

Dessa perspectiva, surgiram trabalhos procurando ressaltar os aspectos virtuosos da retomada do ativismo estatal no Brasil, associando esse movimento à retomada do crescimento, aumento dos níveis de emprego e redução das desigualdades, com base em dados agregados e eventualmente incorporando outros países latino-americanos à análise (Boschi \& Gaitán 2009). No entanto, seguindo hipóteses semelhantes sobre o papel das instituições, dos atores estratégicos e de outras variáveis políticas, porém desagregando a análise em setores específicos, surgiram também estudos demonstrando que o desempenho do poder público nem sempre foi positivo em termos de promover desenvolvimento ou mesmo bem-estar ${ }^{3}$.

Entre as contribuições que este dossiê pretende trazer ao debate sobre o tema está uma atenção maior não só às potencialidades, mas também aos limites e principalmente às ambivalências representadas pela redefinição do papel do Estado desde o início do século XXI. Ao estabelecer um diálogo entre produções acadêmicas de diferentes latitudes, desenvolvidas em universidades na América Latina e Europa, dialogando ainda com a literatura norte-americana, este dossiê convida o leitor a abordar as relações entre Estado e mercado nos países do Cone Sul em forma comparativa, delineando ainda a perspectiva de ampliação deste exercício comparativo a outros países em desenvolvimento.

Uma das virtudes da abordagem comparativa é precisamente o esforço de olhar para as realidades locais em perspectiva internacional. Esse esforço não só visa superar fixações nacionais, bem como a historicidade dos sistemas acadêmicos locais, mas procura reforçar pontes e estabelecer novos diálogos entre pesquisadores da região. Estudos comparativos nos permitem estudar o outro para lançar luz sobre um e, reciprocamente, um é estudado para lançar luz sobre o outro. É nesta interseção das sombras, e seu ajuste ou incompatibilidade, que uma imagem mais vívida dos casos nacionais ou setoriais emerge. Metodologicamente falando, o olhar comparativo é um convite a superar a tentação de encontrar explicações endógenas, particularistas, excepcionais, destacando tanto os elementos comuns como as diferenças nas relações entre nações ou setores.

O dossiê é composto por cinco artigos. Os dois primeiros utilizam métodos comparativos para abordar problemáticas comuns dos países latino-americanos (Undurraga), comparando as experiências do neoliberalismo no Chile e Argentina, e do sul global (Leubolt), comparando os discursos sobre a desigualdade no Brasil e na África do Sul. Os três artigos seguintes empreendem estudos de caso sobre políticas públicas e aspectos específicos das relações entre Estado e mercado no Chile (Maillet) e no Brasil (De Toni e Klüger).

O artigo de Tomás Undurraga contrasta as trajetórias divergentes do neoliberalismo na Argentina e no Chile. O autor se pergunta por que dois países que 
implementaram reformas de mercado aparentemente semelhantes, e que durante os anos 1990 eram celebrados conjuntamente como os "melhores alunos" do Consenso de Washington na região, acabaram com posições diferentes sobre as relações Estado-mercado: uma política pós-neoliberal na Argentina e um neoliberalismo temperado no Chile, que só recentemente, depois das mobilizações sociais de 2011, está sob suspeita. O artigo traça os antecedentes comuns que inspiraram as reformas de mercado desde as ditaduras militares dos anos 1970 e discute os diferentes resultados que essas políticas produziram. Undurraga destaca que as políticas de livre-mercado foram rejeitadas em ambos os países no contexto dos colapsos econômicos de princípios da década de 1980, mas enquanto Pinochet resistiu à pressão social dos protestos, a derrota nas Malvinas contribuiu para o enfraquecimento tanto dos militares como o neoliberalismo na Argentina. Logo, durante os anos 1990, a tecnocracia política da Concertación e a instalação das ideias de Chicago ajudou a construir um consenso neoliberal no Chile, enquanto a tentativa de desencantar a política pela economia não foi capaz de desarmar a textura coletiva das redes peronistas na Argentina. Mais importante, o neoliberalismo produziu diferentes resultados e respostas: foi associado com progresso material no Chile, e com a pior crise política, social e económica na Argentina, como foi o colapso do 2001. Finalmente, o autor considera que enquanto as elites empresariais seguiram defendendo a modernização capitalista no Chile, a contraofensiva liderada pelos Kirchners enfraqueceu ainda mais o neoliberalismo e a classe empresarial na Argentina. De um ponto de vista teórico-metodológico mais geral, o artigo sugere atentar não só para as trajetórias particulares que as relações Estadomercado e seus modelos assumem em diversos países, mas também para a complexidade e hibridização do próprio projeto neoliberal e seu caráter adaptativo.

Na sequência, o trabalho de Bernhard Leubolt analisa a relação entre os discursos e as instituições sobre a desigualdade no Brasil e na África do Sul. De forma a conectar os elementos materiais, simbólicos e culturais da produção e reprodução social das desigualdades nesses paises, o artigo interliga diferentes perspectivas teóricas - i.e. institucionalismo histórico e economia política cultural - conformando uma abordagem estratégico-relacional. Ele se concentra na comparação de discursos sobre a desigualdade no Brasil e na África do Sul, procurando revelar as raízes históricas das construções discursivas de desigualdade e igualdade e a influências destas sobre as políticas relacionadas à desigualdade. Enquanto a África do Sul é vista como um exemplo de discriminação racista formal, o regime de desigualdade brasileiro funcionou com base em padrões mais informais. As diferentes heranças históricas influenciam o atual enfoque das políticas de promoção da igualdade, que nos últimos anos tendem a ser predominantemente anti-racistas na África do Sul, enquanto tendem a ser mais focadas na redução da pobreza no Brasil. A experiência brasileira tendeu mais a um discurso de "interesse comum" e foi mais capaz de institucionalizar políticas de redução da desigualdade de renda. A experiência sul-africana, por sua vez, permanece sendo discursivamente dividida em "duas nações". Segundo o autor, a ascensão social para os grupos ligados aos partidos governistas foi apenas parcialmente acompanhada por melhores condições de vida para a maioria pobre dos sul-africanos. Como conclusão, o artigo argumenta que a criação e a redução das desigualdades em ambos os países são estruturados em boa medida pelas heranças históricas. O discurso brasileiro de "uma nação" foi mais bem sucedido na promoção de políticas de igualdade do que no caso do discurso de "duas nações" na África do Sul. A despeito de melhorias importantes, ambos os países se encontram em conjunturas críticas e as contradições sociais começam a criar novas tendências de crise. 
$\mathrm{O}$ artigo de Antoine Maillet traz o foco novamente para a América Latina, mais especificamente, para o Chile. Ao contrário das leituras nacionais que tendem a analisar as relações Estado-mercado a partir da noção de "modelo" ("modelo neodesenvolvimentista" no Brasil, "modelo nacional-popular" na Argentina, o "modelo neoliberal" no Chile), o autor afirma que as políticas públicas em relação aos mercados são geralmente heterogêneas dentro desses modelos, dependendo dos setores da economia e de suas peculiaridades. Inspirado pela abordagem de Snyder (2001) para superar o "viés da nação inteira" e estudar as realidades sub-nacionais, Maillet compara as trajetórias setoriais de energia elétrica, transporte público de Santiago e pensões, desde a implementação das reformas neoliberais durante a ditadura Pinochet até hoje. O artigo mostra como políticas que começaram a partir do mesmo ponto de origem tomaram caminhos divergentes. A criação de um mercado da eletricidade manteve-se relativamente estável durante quase duas décadas, até os "apagões" de 1998 e 1999. As medidas definidas pelo Estado e os agentes privados para cobrir essas crises, no entanto, não alteraram a relação entre Estado e mercado nesse setor. História distinta segue o transporte público em Santiago, onde após uma década de liberalização, foi introduzido um sistema de concessões na década de 1990 e uma redefinição completa das relações Estado-mercado com a implementação de Transantiago nos anos 2000. O sistema de previdência privada segue novamente um rumo distinto. A série de regulamentos para os Fundos de Seguros de Pensões (AFP) desde a sua criação teve pequenas alterações durante os anos 1990, e um retorno à margem do mercado por parte do Estado após 2008. Assim, o artigo mostra como a suposta coerência e consistência do modelo chileno esconde uma realidade muito mais fragmentada do que é geralmente reconhecido, ao se adotar uma perspectiva de análise setorial.

O artigo de Elisa Klüger, por sua vez, oferece uma análise comparativa das formas e dos sentidos dos termos técnica e política nos discursos de dirigentes e funcionários do $\mathrm{BNDE}(\mathrm{S})$ em dois momentos distintos: de 1952 a 1970 e de 1994 a 2011. A comparação contrasta as diferentes noções das políticas de desenvolvimento e seu principal agente - o banco de desenvolvimento - no auge do estado nacional-desenvolvimentista e após o apogeu neoliberal. A partir do exame de entrevistas com funcionários e dirigentes de ambos os períodos, Klüger argumenta que há uma transição no padrão dos discursos. Inicialmente havia uma oposição da burocracia aos políticos, que decorria da percepção de que haveria uma superioridade de uma burocracia qualificada para tomar decisões político-econômicas. No segundo período, pós-redemocratização, o discurso expressa a tensão gerada pela necessidade simultânea de responder aos governantes e de agir de modo a preservar os valores, a missão histórica do Banco e a excelência técnica contra ingerências políticas que pudessem ameaçar a instituição. Neste segundo momento não é o credenciamento dos burocratas e sim o refinamento das técnicas por eles empregadas que é mobilizado como recurso para justificar as decisões econômicas dos burocratas. As oposições encontradas foram lidas à luz das teorias críticas de Pierre Bourdieu e Herbert Marcuse, que permitem questionar o caráter meritocrático dos especialistas em economia e a neutralidade da ciência e das técnicas por eles empregadas. $\mathrm{O}$ artigo contribui para o estudo da relações entre política e burocracia no Brasil através do estudo de um caso paradigmático. Ele permite verificar como a lógica da relação de oposição entre as esferas da técnicaciência e da política se altera ao longo do tempo e busca, através de uma análise crítica dos dados, avaliar quais seriam os fundamentos sociais dessa transformação.

Encerrando o dossiê, o artigo de Jackson de Toni tem como objetivo verificar as variáveis capazes de explicar um padrão virtuoso de relacionamento 
público-privado na produção de políticas públicas relacionadas à política industrial durante o primeiro governo Lula (2003-2006). O argumento central dessa pesquisa é que o Conselho Nacional de Desenvolvimento Industrial (CNDI), vinculado ao Ministério do Desenvolvimento, Indústria e Comércio Exterior (MDIC), como arena público-privada de política industrial, legitimou-se como o lócus da agenda de política pública. Essa situação resultou da combinação de dois processos políticos distintos: a influência das ideias neodesenvolvimentistas, em especial aquelas da nova política industrial, e a ação de empreendedores políticos. A pesquisa foi baseada no estudo da dinâmica de funcionamento do CNDI, enfatizando-se o papel do fórum na formulação e implementação de medidas ligadas ao incentivo à inovação (Lei do Bem, Lei da Inovação, Fundos Setoriais). Os dados foram obtidos pela análise das atas do colegiado, análise documental e entrevistas com os atores envolvidos. Os relacionamentos estabelecidos e a formação da agenda de política no conselho contribuiu para a definição da política industrial do período. O papel dos empreendedores políticos e do ideário neodesenvolvimentista contribui para a viabilidade dessa dinâmica. Assim, o artigo ajuda a entender o funcionamento dos fóruns tripartites de políticas públicas em contextos democráticos, as causas aparentes de seus êxitos e fracassos.

Além de oferecer um panorama dos estudos contemporâneos sobre o tema a partir de uma perspectiva comparativa e internacional, o dossiê é um convite à renovação da pesquisa na área e à maior interlocução entre os diferentes grupos com esse interesse comum. Dentre as contribuições que os artigos oferecem em termos da agenda de pesquisa, estão o uso de metodologias comparativas, a atenção à questão das desigualdades como parte inseparável do debate sobre o desenvolvimento, além da centralidade da dimensão política como variávelchave da relação entre Estado e mercado. Diante das reviravoltas da trajetória política latino-americana e do maior protagonismo dos países em desenvolvimento na última década, contrariando os discursos fatalistas sobre a globalização e o neoliberalismo, não apenas as elites e estruturas de poder ligadas ao capital se viram desafiadas, como também a Sociologia Econômica enfrenta o desafio de se renovar e seguir oferecendo respostas para as questões colocadas por seu tempo. Consideramos este dossiê um esforço nesse sentido, tanto pelos resultados apresentados, quanto pelas portas que pretende abrir.

Desejamos aos leitores da Revista de Sociologia e Política uma boa leitura!

Cristiano Monteiro (fonsecamonteiro@yahoo.com.br) é Doutor em Sociologia pela Universidade Federal do Rio de Janeiro (UFRJ) e Professor Associado do Programa de Pós-Graduação em Sociologia e do Mestrado Profissional em Administração na Universidade Federal Fluminense (UFF). Afiliação Institucional: Universidade Federal Fluminense, Niterói, RJ, Brasil

Tomás Undurraga (t.undurraga@ucl.ac.uk) é Doutor em Sociologia pela Universidade de Cambridge (Reino Unido) e pesquisador de pós-doutorado no Departamento de Estudos Sociais da Tecnologia na University College London (Reino Unido). Afiliação Institucional: University College London, Londres, Reino Unido.

\section{Referências}

Ahumada, J., 1958. En vez de la miseria. Santiago: Editorial del Pacífico.

Boschi, R. \& Gaitán, F., 2009. Politics and Development: Lessons from Latin America. Brazilian Political Science Review, (3)2, pp. 11-29.

Bresser-Pereira, L.C., 2007. Novo desenvolvimentismo e ortodoxia convencional. In E. Diniz, ed. Globalização, Estado e desenvolvimento: dilemas do Brasil no novo milênio. Rio de Janeiro: FGV.

Burdick, J.; Oxhorn, P. \& Roberts, K., 2009. Beyond Neoliberalism in Latin America? Societies and Politics at the Crossroads. New York: Palgrave Macmillan.

Cardoso, F.H., 1972. Empresário industrial e desenvolvimento económico no Brasil. São Paulo: Difel.

Cardoso, F.H. \& Faletto, E., 1969. Dependencia y desarrollo en America Latina: ensayo de interpretación sociológica. Cidade do México: Siglo Veintiuno Editores.

Chang, H.-J. \& Grabel, I., 2004. Reclaiming Development: An Alternative Economic Policy Manual. Zed Books: New York. 
Cruz, V., 2010. Saúde suplementar no Brasil: a mão do Estado na regulação dos planos privados de saúde. In $7^{\circ}$ Encontro da $A B C P$. Recife.

Diniz, E., 2007. O pós-Consenso de Washington: globalização, Estado e governabilidade reexaminados. In , ed. Globalização, Estado e desenvolvimento: dilemas do Brasil no novo milênio. Rio de Janeiro: FGV. 2000. Globalização, reformas econômicas e elites empresariais. Rio de Janeiro: FGV.

Domingues, J.M., 2008. Latin America and Contemporary Modernity. London: Routeledge.

Faoro, R., 1976. Os donos do poder: formação do patronato político brasileiro. Porto Alegre: Globo.

Fernandes, F., 1976. A revolução burguesa no Brasil. Rio de Janeiro: Jorge Zahar Editor.

Furtado, C., 1964.Dialética do desenvolvimento.Rio de Janeiro: Fundo de Cultura.

Gentili, P., ed., 2000. Globalização excludente. Desigualdade, exclusão e democracia na nova ordem mundial. Petrópolis: Vozes.

Germani, G., 1964. La sociología en la America Latina: problemas y perspectivas. Buenos Aires: Editorial Universitaria de Buenos Aires.

Gomide, A. \& Pires, R., eds. 2014. Capacidades estatais e democracia: arranjos institucionais de políticas públicas. Brasília:IPEA.

Hollanda, S.B., 1995. Raízes do Brasil. São Paulo: Companhia das Letras.

Ianni, O., 1965. Estado e capitalismo. Rio de Janeiro: Civilização Brasileira.

Leme, A., 2009. Estado e reformas orientadas para o mercado: compassos e (des)compassos da reestruturação do setor elétrico brasileiro na década de 1990. Teoria \& Pesquisa, (18)2, pp.182-196.

Macdonald, L. \& Ruckert, A., 2009. Post-Neoliberalism in the Americas. Basingstoke, UK: Palgrave Macmillan.

Martins, L., 1968. Industrialização, burguesia nacional e desenvolvimento. Rio de Janeiro: SAGA.

Montecinos, V. \& Markoff, J., eds., 2009. Economists in the Americas. Northhampton, MA: Edward Elgar.

Monteiro, C., 2009. Estado e mercado no transporte aéreo brasileiro pós-reformas. Política \& Sociedade, (8)15, pp.117-143. ,2010. A dinâmica das relações entre Estado e mercado no transporte aéreo brasileiro (1990-2010). In W. Mancuso; M.A. Leolpoldi; W. Iglecias, eds. Estado, empresariado e desenvolvimento no Brasil: novas teorias, novas trajetórias. São Paulo: Editora de Cultura.

Parsons, T., 1964. Societies: Comparative and Evolutionary Perspectives. New Jersey: Prentice-Hall.

Pinto, A., 1959. Chile, un caso de desarrollo frustrado. Santiago: Ed. Universitaria.

Prebish, R., 1950. The Economic Development of Latin America and its Principal Problems. New York: Lake Success.

Silva, E., 2009.Challenging Neoliberalism in Latin America. New York: Cambridge University Press.

Snyder, R., 2001.Politics after Neoliberalism: Reregulation in Mexico. Cambridge. UK: Cambridge University Press.

Undurraga, T., 2014. Divergencias: trayectorias del neoliberalismo en Argentina y Chile. Santiago: Universidad Diego Portales.

Wallerstein, I., 1979. The Capitalist World-Economy. Cambridge, UK: Cambridge University Press.

License information: This is an open-access article distributed under the terms of the Creative Commons Attribution License (CC-BY-NC 4.0), which permits unrestricted use, distribution, and reproduction in any medium, provided the original work is properly cited. 